\title{
Le plus européen des Tchèques : Jan Amos Comenius (1592-1670)
}

\section{Claire Madl}

\section{(2) OpenEdition}

1 Journals

Édition électronique

URL : http://journals.openedition.org/rbnu/710

DOI : $10.4000 /$ rbnu. 710

ISSN : 2679-6104

Éditeur

Bibliothèque nationale et universitaire de Strasbourg

\section{Édition imprimée}

Date de publication : 1 novembre 2017

Pagination : 96-99

ISBN : 9782859230678

ISSN : 2109-2761

\section{Référence électronique}

Claire Madl, « Le plus européen des Tchèques : Jan Amos Comenius (1592-1670) », La Revue de la BNU [En ligne], 16 | 2017, mis en ligne le 01 juillet 2019, consulté le 31 décembre 2020. URL : http:// journals.openedition.org/rbnu/710 ; DOI : https://doi.org/10.4000/rbnu.710

\section{(c) (i) (2) (2)}

La Revue de la BNU est mise à disposition selon les termes de la Licence Creative Commons Attribution - Pas d'Utilisation Commerciale - Partage dans les Mêmes Conditions 4.0 International. 
2

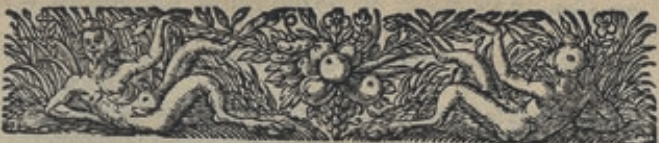

I A N V A

L I NGV A R VM, referata Aurea.

Dic erôffinete oder autf-gefchloficne (3)!, Dene Epraçen-thür.

\section{Introitus.}

\section{Der Eingang.}

2. SAive LECTOR A. mice.

2. Si rogas quid fit eruditum Sort gegrúfec, frcunbetider ties

So bu fragft/mas da fengetefyre efle ? refponfum habe, noffe fonn? So babe jur antwoat : s5 fer rerum differentias, \& poffe u- oer binger vnber [deibe twiffen/ ynoe numquodque fuo defignare vel sin jebcs mit feinem nabmen nen, infignire nomine. new ober bejeiffnen edonnen.

3. Nihilne praterea? Nil cer- Ridjes bann meft? Ticin wats té quicquam.

(id) gar nidits.

4. Totius eruditionis pofuit Der Gat bet gantzen ober affer fundamentum, qui nomencla- geísidtigetit grunbergeteget / wels curam retum nature \& attis dert Die nabinen-nemnung oer $\Re$ ra perdidicit. tur vote bet tunft. fadyen fortig ges tclornec bate.

5. Sed (atqui) id difficile for- 2fber bas ift viltetcht fótwer? (anis

6. Eft: fi invitus fecetis, aut Sa/csiff atfo/ mann bu es vm, praveniente \& preconceptâ willtia vnot twiber beinen wiflen imaginatione teipfŭ cerrueris. thun/ ober mit vorgcfafter meinung oidf ferbften fóseden wirft.

7. Tandem, fi quid alperita- Enbetid to was fóptwet / taub tis erit, initio erit. oter untieblich fepn witot/fo twirbts anfänatió fenn.

8. Annon \& literarum cha- Steinen niche auc oer budi. tacteres ac duCtus pueris primo ftaben jeldent form vnot súge ben intuitu mira monftra \& por- tindern im erfen anbitie fetthame tenta videntur? nunber su fenn.

9. Aft abi paululum impen- 230 ober wann fie aber sin wes
derint

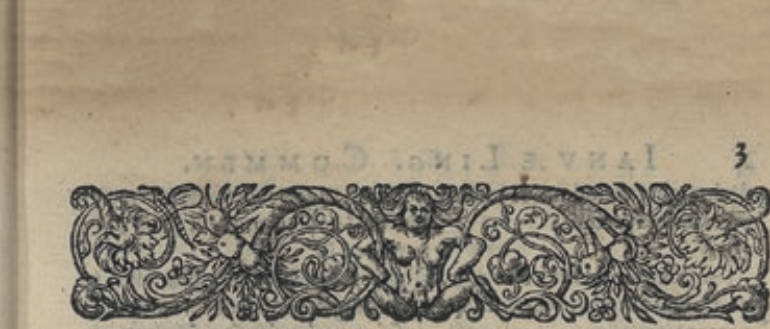

L'EXCELLNTE LECCELLENTE

\section{P ORTE DES PORTA DELLE Langues ouverte. \\ Lingue aperta.}

\section{L'entree.}

L'entrata.

D I 1 u te gard, cher amy Le- Iddio ti guardi, caro amico Ateur. 1 Letiore.

Si tu demandes que c'eft que d'e- Se tou domandi che cofa fial' efftre fçavant ? aye pour refponfe, gue fer' erudito letterata \& ammacc'eft igayoir les differences des cho- frratas habbi per rifposta, il ben fes, \& , pouvoir marquer ou nom- faper le differenze delle cofe, e'l poo. mer une chafcune d'icelles par fon ter fegnare e notare ogniana dal propre nom.

fua propicia nque.

N'y a-il rien d'avantage? non cer- Niente altro dipik, eltra di tes, rięn da tout. $\quad$ quecfo? Non certo, nollas affatto.

De toute Science \& erudition a Di tutta dottrina feienza of mis \& pofé le fondement, celay qui eruditione ba pasto il fundamena parfaittement bien apprisla No- to, chi perfettamente ha impera menclature des chofes naturelles \& ta la nomenclatsra delle cofendartificielles. turali of artificiali.

Mais cela eft peut eftre malaifé \& Ma cio c forfo difficile e madifficile? lagenole?

Ouy, auffi eft il, fi tu le fais envy Si ben, fe lo farai maloolon- mente, \& malgé́ toy, ou fipar une preal- tieri* \& contra twa voglia , ófe con mala lable, \& preconceuë imagination con una preueniente e preconcetta voglia. (un prejugé) tu t'efpourantes toy opinione, tu ti /pasuenti \& im- Contre mefme. paurifci te feffo.

En fin ${ }^{\prime}$ 'il y a quelque alpreté Finalmente, fevi farà qual- * Finaleou rudefle, elle fera au commence. che afperita, ó rwsidezza ella fa- ment. rà al principis.

Auffi les caracteres \& traits de Eticaratterie tratti delle letlettres pe femblent ils pas de premier tere, non paiono anco quelli $d i$ abord des merueilleux monftres, \& prima vifta maranigliofis moftri

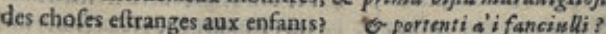

Mais aptes qu'ils y ont employé Ma doppo hasuerwi impiegato

I. A. Comenii Janua aurea reserata quatuor linguarum, sive compendiosa methodus latinam, germanicam, gallicam \& italicam linguam perdiscendi..., Lugduni Batavorum [Leyde],

ex officina Elseviriorum, 1640 
RÉPUBLIQUE TCHÈQUE

\section{LE PLUS EUROPÉEN DES TCHÈQUES : JAN AMOS COMENIUS (1592-1670)}

PAR CLAIRE MADL

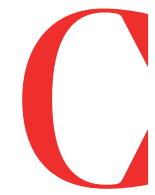

omme toutes les grandes bibliothèques européennes, la BNU possède une centaine d'éditions des œuvres de Jan Amos Komenský, en latin Comenius, dont une vingtaine parues au $17^{\mathrm{e}}$ siècle, outre la trentaine d'ouvrages consacrés à son œuvre. Le « best-seller » ici reproduit est sa Porte des langues, un manuel plurilingue, imprimé pour la première fois en 1631 à Leszno en Pologne et réédité aussi longtemps que les écoliers européens durent maîtriser le latin pour entrer à l'université. La BNU possède cinq Portes dont la belle édition des Elzevier (Leyde, 1640) reproduite ici ${ }^{1}$. Son auteur incarne aussi bien des éléments fondamentaux de l'identité des Tchèques aujourd'hui qu'un pan de l'histoire de l'Europe et certaines de ses valeurs. Comenius a donné son nom à des écoles et universités ; il a ses musées, son centre de recherche et sa revue de coméniologie. La médaille de l'UNESCO récompensant des acteurs de l'éducation porte son nom. Ses aphorismes pédagogiques sont placés au fronton des écoles et tous les enfants tchèques apprennent qu'il fut le " précepteur des nations ».
Comenius naît en 1592 à Nivnice, petite ville de la région orientale du royaume de Bohême, la Moravie, et prend dans ses écrits le nom de la ville d'origine de ses parents (Komenský ou Comenius signifie «de Komňa »). Orphelin, il n'accède que tard à l'éducation à laquelle il pouvait prétendre en sa qualité de fils de maître brasseur et de membre d'une Église réformée réfugiée en Moravie : l'Unité des Frères. Fondée en 1457, cette communauté avait recueilli l'héritage radical du mouvement hussite, après la défaite militaire et politique de ce dernier. Après avoir fréquenté l'école de Přerov, Comenius entame sa "pérégrination académique " dans les universités de Heidelberg, Marburg et surtout Herborn. Il revient enseigner à Přerov où il devient pasteur en 1616, puis est nommé à la paroisse de Fulnek en 1618.

Cette même année, la défenestration à Prague des représentants du roi de Bohême et empereur germanique, suivie en 1620 de la défaite des États de Bohême devant les troupes impériales à la bataille de la Montagne Blanche, marque les débuts de la guerre de Trente Ans et de la recatholicisation des pays tchèques. Les troubles atteignent l'est de la Moravie dès 1621, 
poussant Comenius dans la clandestinité puis l'exil. Son premier refuge est en Pologne, à Leszno. Dès les années 1620, Comenius remplit une série de missions diplomatiques et religieuses à la recherche de soutiens pour ses coreligionnaires dont il devient l'évêque. Il entretient des relations avec les membres éminents et les érudits des communautés protestantes d'Europe : Berlin, La Haye, Amsterdam - où il fait réaliser une carte de Moravie plusieurs fois éditée dans les années 1620. Trouvant sans doute dans le travail le sens d'une existence tourmentée, Comenius publie dans ces années un nombre impressionnant d'écrits : la Porte des langues paraît en tchèque en 1629, en latin en 1631, la Grande didactique en $1633^{2}$. Dans les années 1640, Comenius se rend à Londres, refuse une invitation de Richelieu puis gagne les Provinces-Unies, avant de suivre un de ses mécènes en Suède et de se fixer un temps à Elbing près de Gdansk, où il travaille à son École pansophique (Schola pansophica, 16513). De 1651 à 1654, il est invité au collège protestant de Sárospatak par les princes de Transylvanie, les Rákóczi. Il y écrit son manuel illustré, promis à un grand succès, Le Monde en images (Orbis pictus, 1654, dix éditions à la BNU). Leszno étant incendiée en 1656, Comenius gagne définitivement les Provinces-Unies où paraît la version latine de ses Euvres didactiques complètes (Opera didactica omnia, 1657-1658, 4 vol.). Il meurt en 1670.

Son œuvre foisonnante est tout autant au service de sa communauté religieuse (Histoire des persécutions de l'Église de Bohême, Historia persecutionum ecclesiae Bohemicae, $1648^{4}$ ) qu'en dialogue avec les penseurs de son temps. Parmi ses premières publications en tchèque, ses écrits poétiques se distinguent par leur qualité littéraire (Les Affligés, Truchlivý, 1623-1624). Le Labyrinthe du monde et le paradis du cour (rédigé en 1623) met en récit l'appréhension des désordres du monde par un pèlerin qui, au terme de sa pérégrination, dialogue avec le Christ $^{5}$. Il se distingue par sa puissance poétique et la hauteur de son enjeu politique et social. La recatholicisation des pays tchèques chassant de la haute culture la langue tchèque des réformés, l'œuvre de Comenius témoignera pour des générations de la qualité de cette dernière comme langue érudite.

Comenius est néanmoins aussi un penseur pleinement intégré à une "république des lettres » sans frontières. Il y prend position dans des controverses violentes, contre les idées de Descartes et contre les sociniens par exemple (De irenico irenicorum ${ }^{6}$ ). Sensible à un certain millénarisme, il publie des prophéties dont il côtoie les auteurs ( $\operatorname{Lux}$ in tenebris ${ }^{7}$ ), ce qui lui vaut le rejet des penseurs critiques français (Pierre Bayle repris par l'Encyclopédie de Diderot).

Comenius est surtout l'auteur d'un programme de sagesse universelle ou pansophie, au sein duquel l'éducation occupe une place centrale. Cette dernière, grâce à l'accord harmonieux des trois moyens de connaissance (les sens, la raison et la foi), doit permettre de saisir les correspondances entre les choses et notre relation au monde, notre comportement au sein de celui-ci (Consultation générale sur la réforme des affaires qui rendent l'homme humain, De rerum humanarum emendatione consultatio catholica, $1666^{8}$ ). L'éducation est un droit et un devoir pour l'homme qui, par elle, acquiert son humanité, se soustrait aux servitudes, pour cheminer vers l'universel auquel il est destiné. Ainsi l'éducation doit être absolument " sur tout » et " pour tous ». Elle s'adresse sans limite d'appartenance sociale aussi bien aux filles qu'aux garçons, aux esprits talentueux et aux esprits lents. Sur la base de la pratique des communautés réformées dont il se considère le dépositaire et à partir de ses lectures, Comenius construit une méthode précise où l'éducation accompagne la nature dans son œuvre formatrice et s'adapte aux apprenants en matière de rythmes, d'emplois du temps, de méthodes et de classements des savoirs. Elle doit susciter l'intérêt, faire germer les potentiels naturels et non s'imposer par pure autorité (Didactica magna ou Opera didactica omnia). Aujourd'hui encore, on est surpris par ses écrits sur le rôle du jeu et du théâtre à l'école ou sur l'éducation préscolaire (Information sur l'école maternelle, Informatorium školy mateřské, $1630^{9}$ ).

La Porte ouverte des langues donne la priorité à l'usage sur la règle et innove en offrant du vocabulaire placé dans des phrases à la complexité croissante, couvrant les principaux domaines du savoir. Même les jésuites se l'approprieront. Comenius en théorise la méthode dans la Methodus linguarum novissima (1648, deux éditions modernes à la BNU). L'idée forte selon laquelle l'éducation est aussi une affaire politique et de société est reprise explicitement dans la monarchie des Habsbourg lors la mise en place de la scolarisation 
obligatoire à partir de 1774 sous Marie-Thérèse. La tradition de la Réforme, à laquelle appartenait Comenius, n'est sans doute pas étrangère au succès qu'elle eut en Bohême.

Que reste-t-il de Comenius aujourd'hui ? La première réforme du hussitisme étant ce qui distingue l'histoire tchèque de celle du reste de l'Europe, certains penseurs y ont vu un marqueur de l'identité tchèque, l'associant à l'attachement à la démocratie. L'intérêt pour l'Unité des Frères naît ainsi dès les tolérantes Lumières ; il est entretenu par l'historien de la nation František Palacký (1798-1876), puis par le philosophe et premier président de la République tchécoslovaque Tomáš Garrigue Masaryk (1850-1937). Comenius sort indemne des tentatives de récupération du régime communiste. Aujourd'hui encore, les philosophes et les spécialistes de pédagogie analysent ses travaux. Tous ceux qui ont réfléchi à la place des Tchèques en Europe, le philosophe et dissident porte-parole de la Charte 77 Jan Patočka (1907-1977), ainsi que Václav Havel (19362011), ont pu puiser chez Comenius l'impulsion pour chercher à répondre à la situation la plus pressante dans une perspective universelle. Il fut l'objet-refuge des travaux de chercheurs désireux d'échapper au carcan idéologique dans la Tchécoslovaquie communiste (Josef Polišenský, Josef Válka). Il demeure au centre des travaux actuels sur les réseaux savants européens de ce que l'on nomme l'« histoire connectée ».

Nos bibliothèques sont, au bout du compte, les seules aptes à donner une image concrète de celui qui plaçait très haut la mission de l'éducation : nous aider à combler l'abîme entre le labyrinthe du monde et le paradis auquel nous aspirons.

\section{NOTES}
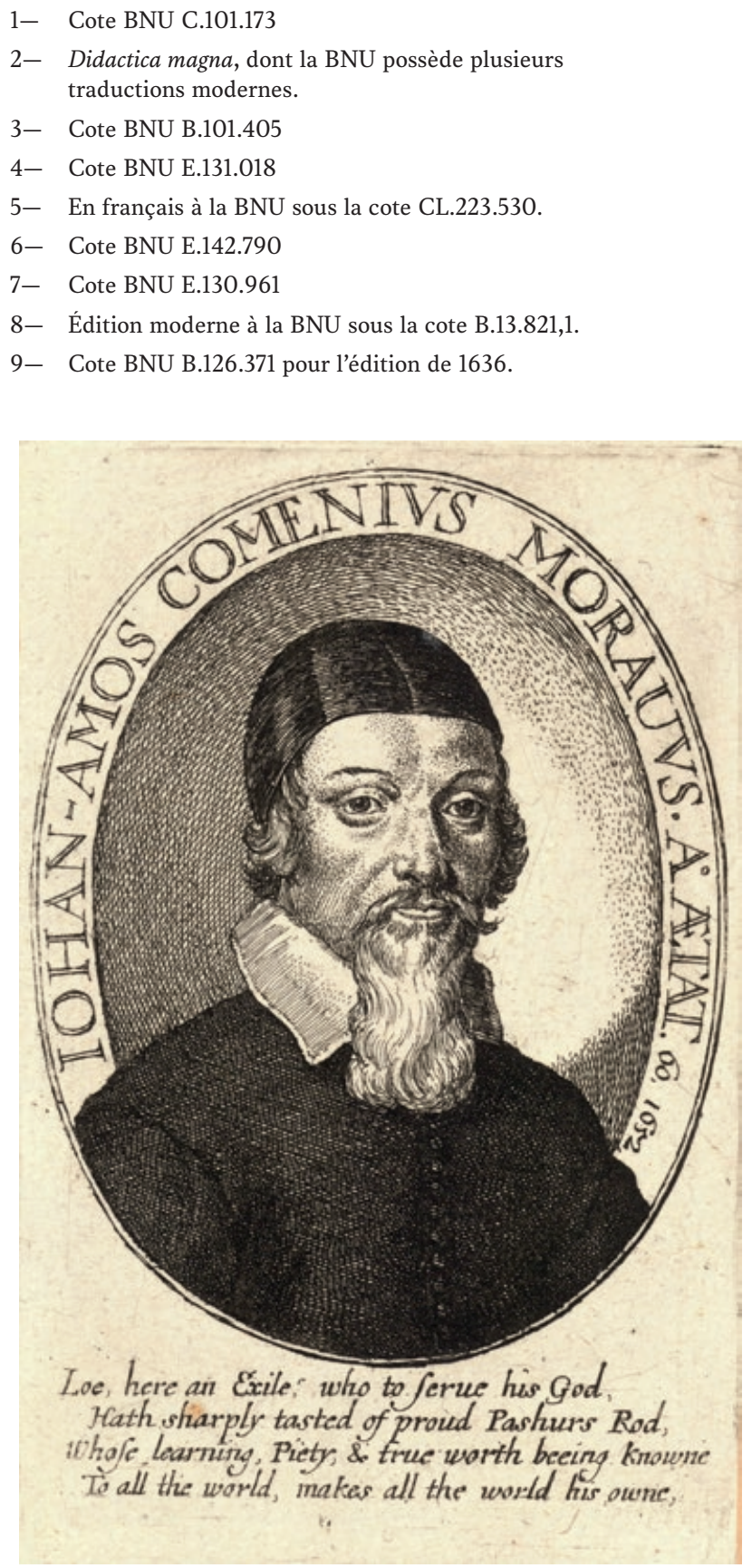

Portrait de Comenius par Wenceslaus Hollar (1652 ; coll. Thomas Fischer Rare Book Library) 